\title{
ECOLOGICAL CARRYING CAPACITY OF LAND USE CHANGES IN DA’AN CITY
}

\author{
Haitao Wang ${ }^{1,2}$, Jinping Zhang ${ }^{3}, \mathrm{Bo} \mathrm{Li}^{2}$ \\ ${ }^{1}$ College of Earth Sciences ,Jilin University, Changchun,China - wseawave@ 163.com \\ ${ }^{2}$ College of Urban and Environment Sciences, Changchun Normal University, Changchun ,China - wseawave@163.com \\ ${ }^{3}$ Songliao Water Resources Commission,China-zhangjp7168@163.com
}

KEY WORDS: Land use, Ecological Carrying Capacity, Da 'an

\begin{abstract}
:
Based on GIS and RS technology, this paper analyzed the land use change in Da 'an city from 1995 to 2010 . land-use ecological evaluation index was constructed to evaluate the land-use ecological risk of Da 'an city dynamically, and the land-use ecological risk level map was made, and then the distribution and change of the land-use ecological carrying capacity pattern of Da'an city were analyzed qualitatively.According to the evaluation results of ecological carrying capacity,the ecological environment of Da 'an city has deteriorated in fifteen years. in 1995, the poor ecological environment area is mainly distributed in the northeast area of Da 'an city, and the area is small, while the area of the central and southern areas is large; In 2010, the western region also appeared environmental degradation, the northeast environment deterioration is serious, the dominant area is reduced, and a small amount of deterioration in the central and southern regions. According to the study of this paper, in the future, we should strengthen the comprehensive management of this part of the area, strengthen vegetation coverage, reduce soil erosion, ensure the effective improvement of ecological environment.
\end{abstract}

\section{INTRUDUCTION}

Based on GIS and RS technology, this paper analyzed the land use change in $\mathrm{Da}$ 'an city from 1995 to 2010 . land-use ecological evaluation index was constructed to evaluate the land-use ecological risk of $\mathrm{Da}$ 'an city dynamically, and the land-use ecological risk level map was made, and then the distribution and change of the land-use ecological carrying capacity pattern of Da'an city were analyzed qualitatively.According to the evaluation results of ecological carrying capacity,the ecological environment of Da 'an city has deteriorated in fifteen years. in 1995, the poor ecological environment area is mainly distributed in the northeast area of $\mathrm{Da}$ 'an city, and the area is small, while the area of the central and southern areas is large; In 2010, the western region also appeared environmental degradation, the northeast environment deterioration is serious, the dominant area is reduced, and a small amount of deterioration in the central and southern regions. According to the study of this paper, in the future, we should strengthen the comprehensive management of this part of the area, strengthen vegetation coverage, reduce soil erosion, ensure the effective improvement of ecological environment.

\section{STUDY AREAR AND DATA}

\subsection{Study Area}

Da'an City is part of the Baicheng City of Jilin Province, located in the northwest of Jilin Province,and in the hinterland of the Songnen Plain, geographical position is $123^{\circ} 08^{\prime} 45^{\prime \prime}$ to $124^{\circ} 21^{\prime} 56^{\prime \prime} \mathrm{E}, 44^{\circ} 57^{\prime} 00^{\prime \prime}$ to $45^{\circ}$. $45^{\prime} 51^{\prime \prime} \mathrm{N}$. The northeast and southwest sides are slightly high and the central part is slightly lower. It belongs to the temperate monsoon climate, and the continental climate is obvious. The average annual sunshine hours is $3012.8 \mathrm{~h}$, annual average temperature $4.3{ }^{\circ} \mathrm{C}$, annual average accumulated temperature $2921.3{ }^{\circ} \mathrm{C}$, the average annual rainfall is $413.7 \mathrm{~mm}$. The soil parent material in the whole area is the Quaternary loess sediments, and its texture is calcareous sand and calcareous clay.

\subsection{Data processing}

Data was derived from the United States land-sat satellite TM remote sensing satellites in the study area in 1995 and 2010, with a spatial resolution of $30 \mathrm{~m}$. The study area 1:150 000 topographic map was selected as the working base map for remote sensing interpretation. Land use status maps, soil maps, and hydrogeological data are used as supporting reference materials.

The remote sensing image is processed in the ENVI software, and the characteristics of each pixel are calculated using the Basic Tools-Statistics-Computer Statistics. Based on the correlation analysis of each band and the size of the information carrying capacity of the plant, the 5, 4, and 3 (RGB) band synthesis is selected. At ArcGIS 9, under the premise of ensuring the same coordinate system, the extracted Da'an City administrative area boundary file is converted into a raster format file using the Vector to Raster tool, and the Masking $\rightarrow$ build mask tool in ENVI is used to represent the border raster of the administrative area as Masking, cropping of two TM images to generate regional image maps of Da'an City in 1995 and 2010.

In ENVI, according to the complexity of the plan classification, the Maximum Likelihood Classification is adopted. The method firstly assumes that the statistical results of each spectral information in the remote sensing image are normally distributed, and then calculates the value of any pixel merging into each type of ROI, and finally categorizes according to the magnitude of the numerical value. Import the classified result into ArcGIS 15.2 for vectorization and chart output. The result is followed in Figure 1-2. 


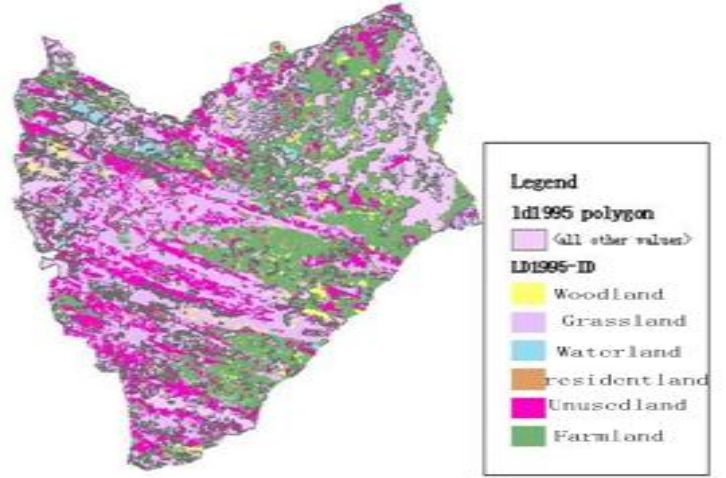

Figure 1. Land use in1995

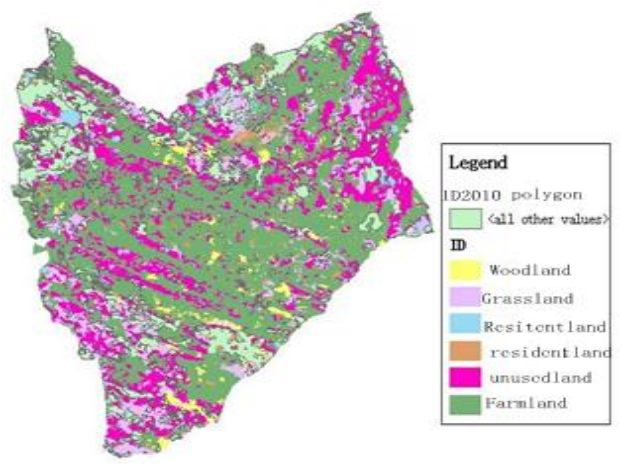

Figure2. Land use in2010

\section{ECOLOGICAL CAPACITY AND FACTORS}

The ecological carrying capacity includes two basic meanings: The first layer of meaning refers to the self-sustaining and selfregulating capacity of the ecosystem, and the capacity of the resource and environment subsystems to support the ecological carrying capacity; the second layer of meaning refers to The development capability of the socio-economic subsystems within the ecosystem is the pressure part of the ecological carrying capacity( Botequilha LA, Ahern J. 2002).

The self-sustaining and self-regulating capabilities of ecosystems refer to the elasticity of ecosystems. The capacity provided by subsystems for resources and environment refer to the carrying capacity of resources and the environment, respectively(Jixi Gao. 2001). The development capabilities of the socio-economic subsystems refer to the sustainability of ecosystems. The size of the social economy and the number of people with a certain standard of living.

\subsection{Vegetation index}

With regard to the setting of the ecological carrying capacity of land, the vegetation index is a basic ecological indicator. The NDVI index can effectively reflect the vegetation coverage in the study area. The effective formula for NDVI is as follows:

$$
N D V I=\frac{N I R-R}{N I R+R}
$$

NIR and R are near-infrared and red light bands. Use ENVI's band math tool, enter the above formula, and specify the NIR and $\mathrm{R}$ bands respectively.

\subsection{Abundance index}

The abundance index is a biological indicator that measures the regional ecological carrying capacity. The specific calculation formula is followed :

Bioabundance index $=$ Abio $\mathrm{x}(0.5 \mathrm{x}$ forest area $+0.3 \mathrm{x}$ water area $+0.15 \mathrm{x}$ grass area $+0.05 \mathrm{x}$ other area)/area area, where Abio represents the normalization coefficient of the biological abundance index.

\subsection{River network density}

The river network density refers to the ratio of the total length of rivers in the basin to the basin area, or the total length of natural and artificial rivers within a unit area. The ratio of the length of the total river length to the drainage area in the basin or the total length of natural and artificial rivers within a unit area.

Water network density index $=$ Ariv $\times$ river length $/$ area area + Alak $\times$ lake bank (offshore) Area / area area + Ares $\times$ water resources volume / area area Where: Ariv, normalization coefficient of river length;

Alak, the normalized coefficient of lake area;

Ares, normalized coefficient of water resources

\subsection{Ecological capacity evaluation}

Based on the various evaluation factors that have been set, the calculation of the weights of the ecological carrying capacity factors is carried out, and the evaluation formula of the ecological carrying capacity of Da'an City is obtained:

$$
P_{n}=X_{1} \sum a_{n} \times P C 1+X_{2} \sum b_{n} \times P C 2
$$

Where $\mathrm{P}$ is the bearing capacity and $\mathrm{n}$ is the year. $\mathrm{X} 1$ represents the eigenvalue contribution rate, an and bn represent the value of each factor, and $\mathrm{PC} 1 / \mathrm{PC} 2$ represents each factor weight.

\section{RESULTS}

\section{1 land use change analyze}

Using the ENVI platform to extract remote sensing images from 1995 and 2010 respectively, obtaining the current land use status, and further processing the image to obtain the land use transfer matrix, and then extracting the data from the land use transfer matrix to obtain land in Da'an City.

\begin{tabular}{|c|c|c|c|c|c|c|}
\hline Year & Farmland & Grassland & $\begin{array}{c}\text { Wood } \\
\text { land }\end{array}$ & $\begin{array}{c}\text { Residentia } \\
1 \text { land }\end{array}$ & Water & Unused \\
land \\
\hline 1995 & 206742 & 332385 & 43785 & 17496 & 20240 & 225606 \\
\hline 2010 & 395332 & 152419 & 55022 & 20394 & 19883 & 201349 \\
\hline Variation & 188590 & -179966 & 11237 & 2898 & -356 & -24257 \\
\hline
\end{tabular}

Table 1. Land use change of Da'an City from1995 to 2010

In table1, It can be seen that land use have changed significantly. In 15years, Farmland land in Da'an City increased significantly, with a net increase of $188590 \mathrm{hm}^{2}$. The forest land also changed significantly, with a net increase of $11,237.3 \mathrm{hm}^{2}$, and the residential land and industrial and mining land did not change 
significantly. The net increase was $2,898.2 \mathrm{hm}^{2}$. In the past 15 years, the grassland has been significantly reduced, with a net decrease of $179966.1 \mathrm{hm}^{2}$. Unutilized land is also decreasing. The net reduction is $24257.2 \mathrm{hm}^{2}$. The water change is not obvious, and the net reduction is $356.2 \mathrm{hm}^{2}$.

In the past 15 years, the types of land use transfer in Da'an has been significant. The increase in woodland mainly comes from farmland land. This change shows that in the past 15 years, Da'an City has made significant efforts to improve the ecological environment and actively promote the construction of ecological forest land. The main sources of increase infarmland land are grassland and unused land, which reflects the pressure of the overall ecological deficit in Da'an City. The per capita food demand continues to increase, and the local ecological pressure is prominent. The main sources of increase in residential areas and industrial and mining land are farmland, grassland and unused land, reflecting the results of the urbanization process in the study area.

With the economic development, the increase in the number of people, the speed of urbanization in the study area has accelerated, and the occupation of surrounding farmland land and grassland resources has become increasingly serious.

\subsection{Abundance index}

The land abundance index is a basic indicator of land ecology and is used to indicate the difference in biological species per unit area of the ecosystem. Specifically, the level and density of various ecological land types are distributed. According to the differences in the distribution of biological species in different land types, we assign $0.25,0.15$, and 0.3 weights to farmland land, grassland, and forest land, and to the bare land of buildings. Assigning a weight of 0.05 to get the abundance values for each part of the study area is shown in ArcGIS as follows:

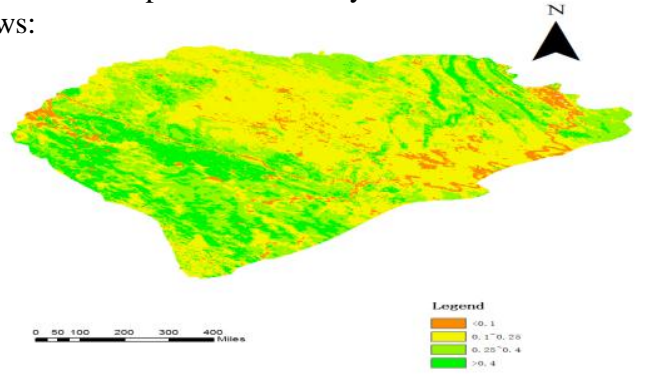

Figure 3. Evaluation of abundance values in 1995

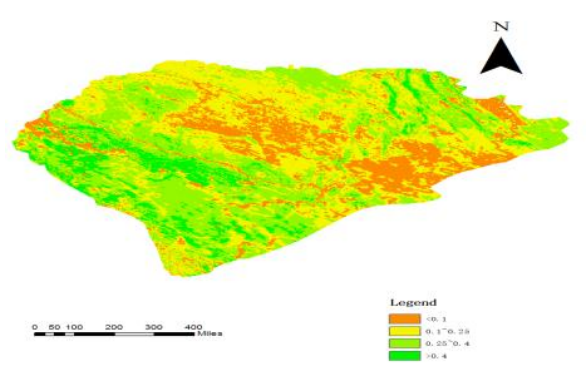

Figure 4. Evaluation of abundance values in 2010 we can see that the overall situation of the abundance index is 1995>2010, which shows that between 1995 and 2010, the land use pattern in Da'an City area has been optimized, and the abundance index has shown a downward trend. In15years, due to certain factors, changes in land use patterns have led to a decline in the abundance index, and the abundance changes in the northeastern region have become more apparent.

\subsection{Vegetation coverage index}

Vegetation coverage is a parameter that can be used to characterize regional vegetation growth and coverage based on the vegetation index. Its distribution is proportional to NDVI, and the greater the index, the better the vegetation growth.

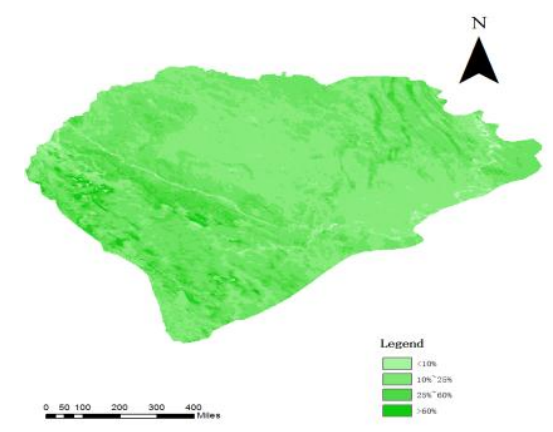

Figure 5. Vegetation coverage evaluation in 1995

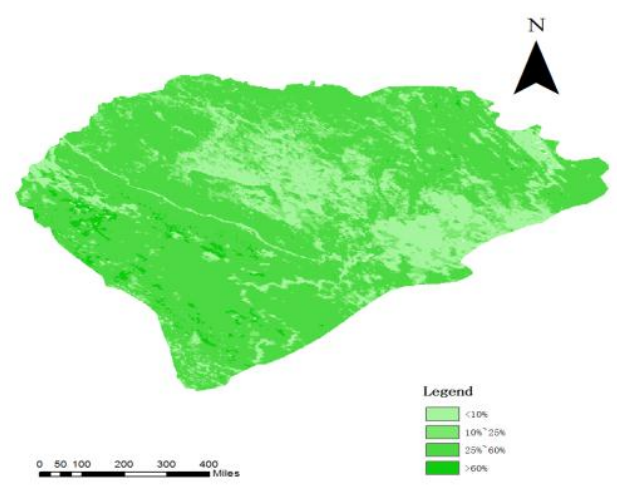

Figure 6.Vegetation coverage evaluation in 2010

It can be seen that the overall situation of the vegetation index is 1995>2010, indicating that between 1995 and 2010, the land use pattern in the Da'an City has deteriorated and the vegetation index has shown a downward trend.

\subsection{Water density}

As one of the important elements in the ecosystem, water density has important decisive significance for the balance of land ecology and the ability to resist disasters. In ArcGIS, the specific calculation method is to divide the land into unit grids, and calculate the water body distribution in the unit grid as a density indicator. 

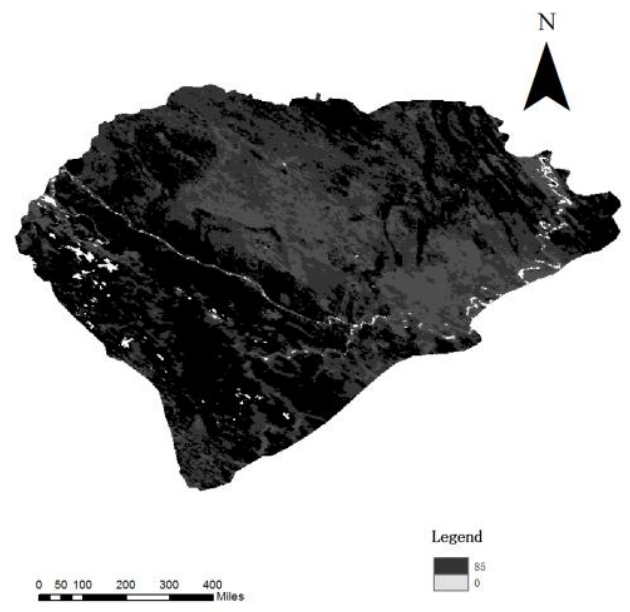

Figure 7.Change in water density in 1995

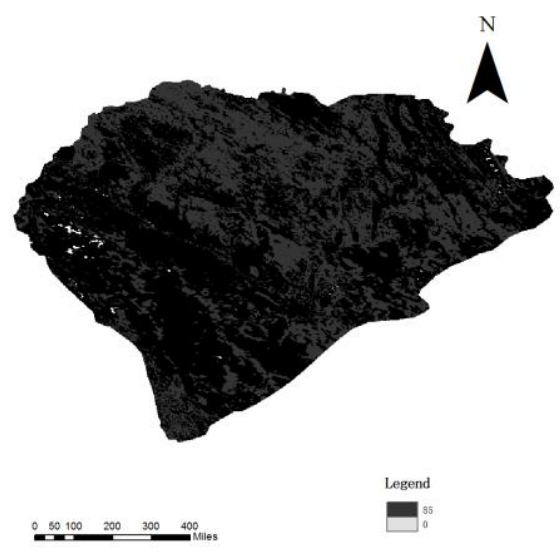

Figure 8.Change in water density in 2010

The change in water density generally shows a downward trend. In the past 15 years, the distribution of water body index has been continuously decreasing, and the total water body density in Da'an City has been decreasing. This shows that the phenomenon of water and soil erosion has been serious in recent years.

\subsection{Soil erosion index}

Soil erosion intensity often explains the important factors of land use pattern and ecological change, and can determine the change trend of vegetation coverage and water density. According to the degree of soil erosion, this paper delineated the criteria of soil erosion, mild (0.025), moderate (0.070), severe (0.3) and severe (0.5), and obtained Da'an soil erosion index map. The specific calculation of the erosion index is based on the spatial distribution of water and soil loss in Da'an City, divided by the unit area, and the water and soil loss index per unit area is displayed in ArcGIS: Mark footnotes in the text with a number (1); use the same number for a second footnote of the paper and so on. Place footnotes at the bottom of the page, separated from the text above it by a horizontal line.

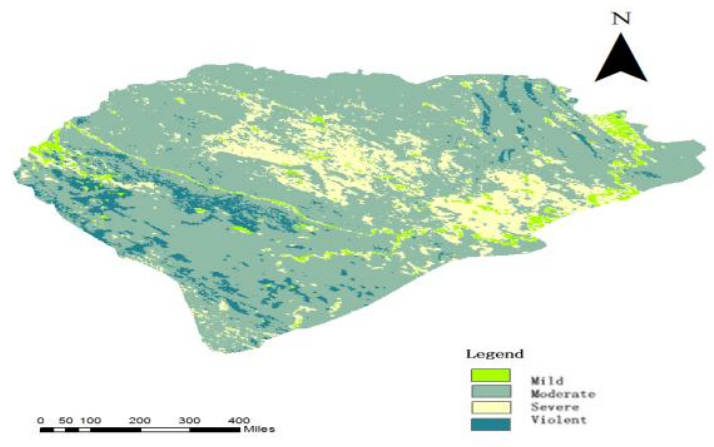

Figure 9.Changes in soil erosion in 2010

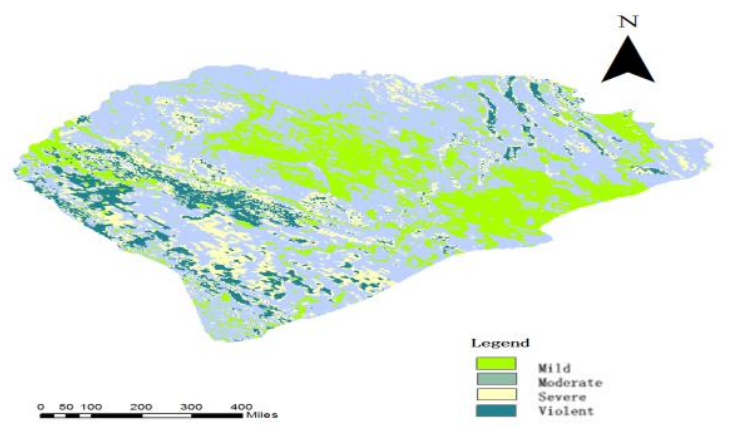

Figure 10. Changes in soil erosion in 1995

\subsection{Human activity index}

The calculation of human activity index is also based on the degree of interference. The greater the degree of interference is, the worse the ecological environment. Based on this, the human activity index is assigned, and the weight assigned to various types of land use is the residential construction land 35 , and the cultivated land. 45 . Unused land 60 , water body 80 , grassland 80 and woodland 85 are displayed in ArcGIS as follows:

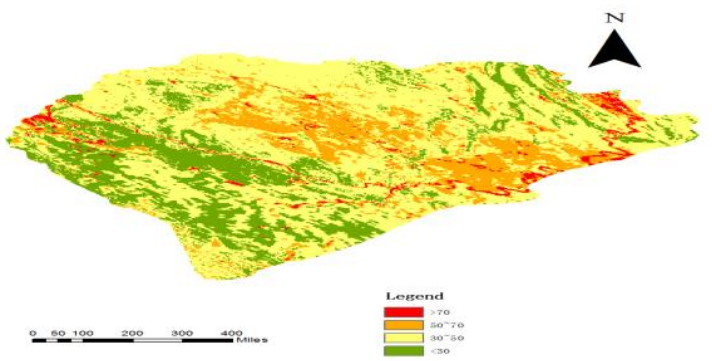

Figure 11.Change in human activity index in 1995

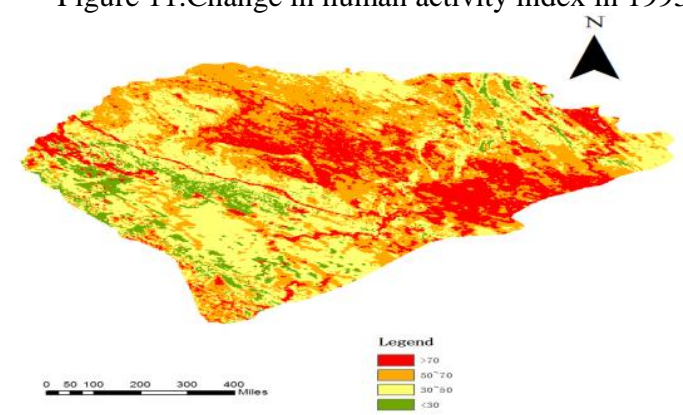

Figure 12.Change in human activity index in 2010 


\subsection{Calculation of Ecological Carrying Capacity Based on Ecological Factors}

In order to analyze the ecological carrying capacity based on the above-mentioned ecological factors, it is necessary to determine the evaluation system of the ecological carrying capacity. According to the principal component analysis method, the weight of the bearing capacity of each factor is calculated, as shown in Table 4-1:

\begin{tabular}{|c|c|c|c|}
\hline YEAR & $\begin{array}{l}\text { Driving Force } \\
\text { Index }\end{array}$ & PC1 & PC2 \\
\hline \multirow{5}{*}{1995} & $\begin{array}{l}\text { Vegetation } \\
\text { cover }\end{array}$ & 0.414 & 0.018 \\
\hline & $\begin{array}{l}\text { Abundance } \\
\text { index }\end{array}$ & 0.008 & 0.201 \\
\hline & $\begin{array}{l}\text { River network } \\
\text { density }\end{array}$ & -0.179 & -0.014 \\
\hline & Soil Erosion & 0.325 & 0.086 \\
\hline & $\begin{array}{l}\text { human } \\
\text { activity }\end{array}$ & 0.841 & 0.412 \\
\hline \multirow{6}{*}{2010} & $\begin{array}{l}\text { Vegetation } \\
\text { cover }\end{array}$ & 0.507 & 0.208 \\
\hline & $\begin{array}{l}\text { Driving Force } \\
\text { Index }\end{array}$ & 0.057 & 0.213 \\
\hline & $\begin{array}{l}\text { Vegetation } \\
\text { cover }\end{array}$ & -0.002 & -0.008 \\
\hline & $\begin{array}{l}\text { Abundance } \\
\text { index }\end{array}$ & 0.279 & 0.035 \\
\hline & $\begin{array}{l}\text { River network } \\
\text { density }\end{array}$ & 0.915 & 0.507 \\
\hline & Soil Erosion & 62 & 27 \\
\hline
\end{tabular}

Table 2. Analysis and Evaluation of Bearing Capacity of

Factors

As can be seen from the above table, the contribution rates of the PCI eigenvalues for both years are all above $60 \%$, indicating that it concentrates most of the characteristics of several driving factors. Judging from the quantitative results, human activities are the most important factor in land use and ecological pattern changes, among which human activities have significantly increased in 1995-2010, resulting in a decline in ecological indicators such as vegetation coverage, river network density, and so on. In the northeastern region, more control over human activities should be strengthened. As the second driving factor, soil erosion also has aggravating trend. Therefore, necessary measures should be taken to rectify the land use pattern in Da'an City.

Based on the weights of the factors in the above table, the assessment formula for the ecological carrying capacity of Da'an City is obtained:

$$
P_{n}=X_{1} \sum a_{n} \times P C 1+X_{2} \sum b_{n} \times P C 2
$$

Where $\mathrm{P}$ is the bearing capacity and $\mathrm{n}$ is the year. $\mathrm{X} 1$ represents the eigenvalue contribution rate, an and bn represent the value of each factor, and PC1/PC2 represents each factor weight.

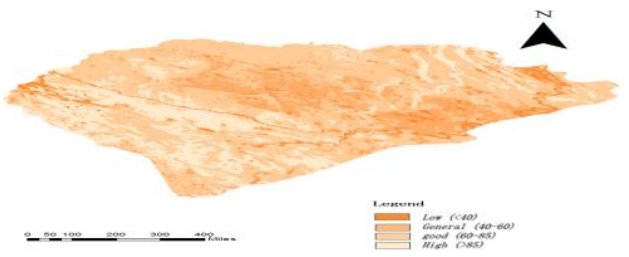

Figure 13.Da'an Ecological Carrying Capacity in 2010

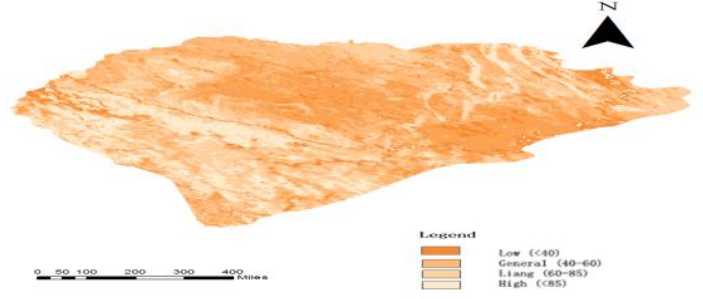

Figure 14 Ecological carrying capacity in 1995

\section{CONCLUSION}

During the ten years, the overall ecological environment of Da'an City has deteriorated. The regions with poor ecological environment in 1995 were mainly distributed in the northeastern region of Da'an City with a small area, while the central and southern regions had a relatively large area of excellent environmental conditions; The environment has also deteriorated in the region. The environment in the northeast has deteriorated severely, the area of advantages has decreased, and a slight deterioration has occurred in the central and southern regions.

According to the results of the evaluation of ecological carrying capacity, it was found that in ten years, the geographical geology and human activities in Da'an increased, leading to the reduction of the overall ecological indicators, the area of poor ecological environment increased, and the situation in the northern and eastern regions was more severe. Therefore, according to the research in this paper, in the future Da'an City's ecological environment treatment, we should increase comprehensive management of this area, strengthen vegetation coverage, reduce soil erosion, and ensure the effective improvement of the ecological environment.

\section{DISCUSSION}

Based on the analysis of remote sensing images of Da'an City in 1995 and 2010, this paper processed the remote sensing images through Arcgis and ENVI software, obtained the status of land use structure, and carried out ecological evaluation analysis of land use from three aspects. The driving force of land use.

The ecological environment quality in the study area is closely related to vegetation coverage, water network density and biological abundance. Vegetation coverage should be restored and the soil and water conservation function should be strengthened. Similarly, the density of water network plays a negative role in the ecological environment, and the water flow should be strengthened. Guide and build water conservancy projects such as ravines and dams to reduce soil erosion. This paper analyzes the changes in land use and ecological patterns from 1995 to 2010 and finds that human activities have increased between 1995 and 2010, and proposed improvements. The research in this paper is conducive to the optimization of the ecological environment based on land use and more effective land use optimization.

\section{REFERENCES}

Bartels G B, Norton B E, Perrier G K., An examination of the carrying capacity concept. Range ecology at disequilibrium, 1993: pp.89-103. 
Singb.A.,Digital Change detection techniques using remotely sensed data, InternationalJournal of Remote Sensing, 1989, 10(6): pp.959-1003.

Richard J. Ellis, Peter W. Scott .Evaluation of hyperspectral remote sensing as a means of environmental monitoring in the St. Austell China clay (kaolin) region, Cornwall, UK.2004. pp.123-127

.M.L.M. Graymore, Neil G. Sipe, Roy E. Rickson. Sustaining human carrying capacity: a tool for regional sustainability assessment. Ecological Economics, 2010, 69(3): 459-468.

PaulW.Urban Sim: Modeling urban development for land use, transportation, and environmental planning. Journal of the American Planning Association, 2002, 68(3): pp.297.

Cohen J.E. Population growth and earth human carrying. Science, 1995, 269: pp. 341-346

Peter Berck, Amnon Levy, Khorshed Chowdhury. An analysis of the world's environment and population dynamics with varying carrying capacity, concerns and skepticism. Ecological Economics, 2012, 73: pp.103-112.

Carpenter SR, Mooney HA, Agard J, Capistrano D, De Fries RS, Diaz S, Dietz T, Duraiappah AK, Oteng-Yeboah A, Pereira HM, Perrings C, Reid WV, Sarukhan J, Scholes RJ, Whyte A. Science for managing ecosystem services: beyond the millennium ecosystem assessment. Proceeding of the National Academy of Sciences of the United States of America, 2009, 106: pp.1305-1312.

Agostini P, Pizzol L, Critto A, D'Alessandro M, Zabeo A, Marcomini A. Regional risk assessment for contaminated sites Part 3: Spatial decision support system. Environment International, 2012, 48: pp.121-132.

.Bartolo RE, Vandam RA, Bayliss BP. Regional ecological risk assessment for australia's tropical rivers: application of the relative risk model. Human and Ecological Risk Assessment, 2012, 18(1): pp.16-46

Berry MW, Flamm RO, Hazen BC, Macintyre RL. A system for modeling land-use change. IEEE Computational Science\&Engineering, 1996, 3(1): pp.24-35.

Dalposso GH, Uribe-opazo MA, Mercante E, Lamparelli RAC. Spatial autocorrelation of NDVI and GVI indices derived from landsat/Tm images for soybean crops in the western of the state of Paraná in 2004/2005 crop season. Engenharia Agrícola, 2013, 33(3): pp. 525-537. 